\title{
Investigation Report on the Teaching of Practical English Writing of English Majors
}

\author{
Xiaojuan Liu \\ College of Foreign Languages, Tianjin Polytechnic University, Tianjin 300387, China \\ E-mail: liuxiaojuan@tjpu.edu.cn
}

\begin{abstract}
The practical writing course aims at helping students have a comprehensive understanding of writing subjects and improve their abilities of analyzing and understanding texts. This paper has explored how writing textbooks are used in the writing course and pointed out that the aim should be to help students improve their ability of analysis and cultural consciousness, increase the amount of reading and improve their ability of summarizing, read more subjects and strengthen their consciousness of stylistics. This paper also noticed some problems in students' writing through the questionnaires and gave further analysis.
\end{abstract}

Keywords: Ability of analysis, Cultural consciousness, Ability of summarizing, Consciousness of stylistics

Practical English writing should be based on students' comprehensive knowledge of English grammar, basic skills of utilizing vocabulary and sentences and their learning and practice of some basic text types. It involves semantics, stylistics, register and social culture as well as pure language knowledge. In this course, in addition to some practical topics, students' writing skills should also be improved; besides five-step articles, they are expected to deal with more advanced academic writing, to collect and produce, analyze and organize information (Williams, 2007). Accordingly, teachers are supposed to carefully search for proper textbooks, practical text types and reading materials for English writing course.

\section{The Basic Themes of the Course}

\subsection{Improving Analysis Ability and Cultural Consciousness}

One of the teaching materials used in this course is College Writing Skills with Readings introduced to China by Foreign Language Teaching and Research Press. In this book, four principles for revising a composition are summarized, including unity, support, coherence and sentence skills. In addition, some exercises related to 9 text types are designed to have a comprehensible level of complexity.

In this book, with both the first and the second drafts offered for each topic, the compiler points out the problems lying in the first draft. In the teaching process, teachers can give students opportunity to read the first draft and state their viewpoints first of all and then have theirs compared with those of the compiler. This is an effective way to improve students' analysis ability and avoid similar problems in their own writing.

In addition, the sample articles chosen by the compiler embody a large amount of cultural information. By reading a lot, students will learn about the hidden cultural connotation as well as enlarge their vocabulary and acquire the native speakers' writing structure. Let's take the topic of "The Hazards of Moviegoing" as an example. For Chinese students, maybe this topic is related to unavailable tickets or the crowd. However, the vocabulary with strong cultural color has impact on students' vision and thinking. First, some examples of western movies are given at the very beginning of the article. For example, Forrest Gump and The Extra-Terrestrial challenge those who are not well informed of western culture. Besides, some specific expressions are used in this article, such as "patrons" is used instead of "moviegoer" and some expressions are used to exhibit American food culture including "bubble gum", "crushed Raisins", "Milk Duds", "concession stand" and so on. When analyzing this article, students' attention should be focused on not only how the author puts his argument across to the readers but the hidden movie culture. Accordingly, teachers are expected to help students to absorb western culture effectively and encourage them to embody their own cultural information consciously in future writing practice.

\subsection{Enlarging the Volume of Reading and Improving Summarizing Ability}

Another material used in this course is Destinations: Writing for Academic Success introduced by China Renmin University Press. In this textbook, each unit is related to a different topic, for which several reading passages are given. Besides, each passage is attached by a summary, hence providing a good chance to practice students' summarizing ability. Teachers give assignments to write a summary, then revise it according to the fixed standards and point out problems lying in it, such as using too many words from the original, misunderstanding the author's words, incomplete 
summary and some omissions. After that, students are made to compare their articles with the sample and find out something they should learn from, such as vocabulary, coherence, transformation of sentence structures and so on. With such practice in reading and comparing passages, students will be able to acquire new vocabulary and correct their errors.

\subsection{Learning a Variety of Subject Matters and Enhancing Stylistic Awareness}

According to the survey conducted by Huiping Cai in 2006, practical writing covers a wide range of subject matters including advertisements, resumes, summaries, book reports, instructions, letters of applying for studying chance, application letters, messages, notices, lost and found notices, essays, invitation letters, business letters, abstracts, experiment reports and so on. A third material is Functional Varieties of English Written by Wenzhong Hu and Zhenfu $\mathrm{Wu}$, which covers a variety of practical writing passages including notices, advertisements, instructions, tourist cards, letters and resumes collected by the compilers from Australia and Britain and therefore is quite interesting.

Another book, English Stylistics by Youzhi Xu, is used together with Functional Varieties of English because there is no theoretical knowledge in the latter while the former compensates for it with its detailed elaboration on the variables and styles of language, formal and informal expressions, speech language as well as advertising language.

\section{Effects}

Students used to hold the opinion that the writing course means only their writing practice by following samples. However, after nearly two terms' experiment and exploration, both students and teachers have realized the great importance of theory in writing. Only with theoretical guidance in material selection and analysis will students' capacity in information analysis be effectively improved. In this specific course, the genre approach is employed (Williams D23), which, appearing in the middle 1980s, involves sample analysis, imitation writing and independent writing as its main steps. First, samples can be employed to introduce a genre and give analysis on its schematic structure. Teachers are expected to focus on the analysis on genre structure, language characteristics, relevant social context and communication goals and to provide students with some necessary knowledge about relevant social culture, history, custom and so on. Through such an analysis process, students will have thorough knowledge about the forms and contents of this genre, hence laying a solid foundation for their future writing practice. Second, teachers as well as students deal with writing passages of this genre together, including reading, research, collecting and sorting out materials and writing. Here imitation writing doesn't mean copying samples but consciously employing the knowledge related to certain genre acquired from the previous step and enabling students to internalize the structure and language characteristics into their knowledge structure. In the third step, students are supposed to conduct a research on a topic and then write a passage of this genre.

After their study on samples, students will compose passages with individual styles. With advertisements as an example, students displayed their talent in their design after learning that an advertisement is made up of illustrations, the heading and the text. It turned out that they created advertisements with Chinese characteristics while English expressions like this--- Selling the bike with tears. When asked to write long passages, if the given topic is related to certain unit in their coursebook, students will begin with summarizing the text and further state their own opinions. For example, they learned from Lesson One in Destinations: Writing for Academic Success some different learning styles and realized their shortage of knowledge in this aspect. As a result, they began their composition with their own shortcomings and then explained their own learning styles (visual, audio and tactile). Although a majority of students still copied many sentences from the text without any change, their sense of making study serve the practical purpose has been constantly improved, desiring to enlarge their range of knowledge by learning the vocabulary and styles of the texts they have read.

In the previous term, students still failed to give a systematic explanation of textual features when analyzing texts. On one hand, they hadn't finished their learning in linguistics, hence lacking the knowledge about textual features; on the other hand, due to my insufficient emphasis on stylistics, students' analysis on some materials seemed too general, superficial and imperfect. Therefore, some theories on stylistics were added this term, including advertisement and speech. From what perspectives should the analysis be conducted since different textual features are displayed in different texts? At this point, I referred to Youzhi Xu's English Stylistics which systematically explains the features of advertisement and speech in syntax, semantics and lexicology. With its help, students tended to sort out the thread of this type of texts instead of simply following the literary contents. In addition to some former remarks like "this passage has a formal style", students have realized in what ways the formal style should be exhibited now. There is no doubt that such a sense of systematic analysis is quite gratifying. For those students who will further their linguistic researches, this may enhance their knowledge in stylistics; for more average students, such an idea will be enhanced that their analysis and evaluation on anything should be based on adequate grounds for others to accept and believe.

\section{Questionnaire Analysis}

I conducted a questionnaire survey in my class at the end of this term to learn about their writing achievements. Finally 
65 valid questionnaires were returned among all the 70 ones distributed to English majors. This survey involved students' overall impression of the writing course, the amount of reading materials, the amount of writing tasks, the difficulty level of writing tasks, the balance between theory and practice, methods of instruction, the revision of students' compositions, students' progress, whether their goals are achieved or not, the influences of the given material on writing tasks, the gap between the sample summary and students' one, what writing tasks are more helpful to improve students' writing level, some factors to be emphasized in reading and some to be considered in writing and so on.

In Table $1,10.77 \%$ of the surveyed students hold a very positive attitude towards this course; $66.15 \%$ hold a positive one. A majority of students' general impression of this course is manifested in the following aspects in Table 2 to Table 9: the amount of reading materials for students, the amount of writing tasks, the difficulty level of writing, the balance between theory and practice, methods of instruction, the revision of students' compositions, students' progress and whether their goals are achieved or not. Most students' choices in the above aspects agree with their impression shown in Table 1 and these data reflect students' objective evaluation on many aspects of this course truly. However, $10 \%$ of the surveyed students feel dissatisfied at some of these above aspects, such as insufficient writing tasks, imbalance between theory and practice, one-fold method of instruction, ineffective revision of students' compositions, students' dissatisfaction at their own progress, failure to achieve their goals and so on. Accordingly, teachers are supposed to improve their teaching methods in the above aspects, to have more interaction with students and therefore to learn about students' demands. Table 10 to Table 14 mainly reflect students' writing achievements based on the genre approach. $27.69 \%$ of the surveyed students claim that the given material has great influences on them in the independent writing step; $61.54 \%$ admit such influences. This shows their intentional utilization of knowledge into their new writing tasks. It is specifically shown in Table 13 and Table 14 that students pay more attention to textural features when reading passages, including cultural elements, profound thought, vocabulary and other information in the proper order and more to profound thought, which is followed by textural features, cultural elements, vocabulary and other information when writing passages. In spite of the different proportions among the elements in Table 13 and 14, students' active reading is obviously shown. Students' least emphasis on vocabulary further supports the result in Table $11: 36.92 \%$ think that there is a large gap between the sample summary and their own ones; $44.62 \%$ think the gap is proper; only $16.92 \%$ think it quite narrow. Actually, it is their ignorance of vocabulary that leads to such a large gap. According to Jessica Williams (2007), students have to acquire new vocabulary in order to compose good summaries. Summary exercise provides a good chance for second language learners to practice their summarizing ability, that is, to try finding proper vocabulary to describe the same thing. Vocabulary accumulation can help to improve students' expressive ability in a variety of subject matters. As is revealed in the survey on what writing tasks are more helpful to improve students' writing level, assignments after reading samples and practical writing tasks come first, which is followed by summaries, book reports, analysis on a passage and other writing tasks. Obviously, students wish to enlarge their range of knowledge on textual features, cultural elements, profound thought and vocabulary and so on, then to internalize them and apply them to their writing practice. Meanwhile, many students' positive attitudes towards writing summaries and book reports prove their desire to read more materials and express them in their own words. In this case, teachers are expected to give proper summary assignments for students to have a comparison between their own summaries with the sample one and finally to find out the gap between the two.

\section{References}

Cai, Huiping. (2006). Investigation and Analysis of Teaching Writing in English in China. Foreign Language Teaching and Research, 9, 21-24.

Herzfeld-Pipkin, Nancy. (2007). Destinations: Writing for Academic Success. Beijing: China Renmin University Press.

$\mathrm{Hu}$, Wenzhong. Wu, Zhenfu. (1995). Functional Varieties of English. Beijing: Foreign Language Teaching and Research Press.

Langan, John. (2007). College Writing Skills with Readings: Sixth Edition. Beijing: Foreign Language Teaching and Research Press.

Williams, Jessica. (2007). Teaching Writing in Second and Foreign Language Classrooms. Beijing: World Publishing Corporation.

Xu, Youzhi. (2005). English Stylistics. Beijing: Higher Education Press.

Table 1. The overall impression of the writing course

\begin{tabular}{|l|l|l|l|l|}
\hline Number/choice & A & B & C & D \\
\hline \multirow{2}{*}{$\mathbf{N}$} & very positive & positive & less than positive & negative \\
\cline { 2 - 6 } & $10.77 \%$ & $66.15 \%$ & $23.07 \%$ & $0 \%$ \\
\hline
\end{tabular}


Table 2. The amount of reading materials

\begin{tabular}{|l|l|l|l|l|}
\hline Numberlchoice & A & B & C & D \\
\hline \multirow{2}{*}{2} & too great & sufficient & adequate & insufficient \\
\cline { 2 - 5 } & $6.15 \%$ & $61.53 \%$ & $27.69 \%$ & $4.62 \%$ \\
\hline
\end{tabular}

Table 3. The amount of writing tasks

\begin{tabular}{|l|l|l|l|l|}
\hline Numberlchoice & A & B & C & D \\
\hline 3 & too great & sufficient & adequate & insufficient \\
\cline { 2 - 5 } & $9.23 \%$ & $36.92 \%$ & $40 \%$ & $13.85 \%$ \\
\hline
\end{tabular}

Table 4. The difficulty level of writing

\begin{tabular}{|l|l|l|l|l|}
\hline Numberlchoice & A & B & C & D \\
\hline \multirow{2}{*}{4} & Too high & good & fair & poor \\
\cline { 2 - 5 } & $1.54 \%$ & $29.23 \%$ & $64.62 \%$ & $4.62 \%$ \\
\hline
\end{tabular}

Table 5 . The balance between theory and practice

\begin{tabular}{|l|l|l|l|l|}
\hline Numberlchoice & A & B & C & D \\
\hline \multirow{5}{*}{5} & very good & good & fair & poor \\
\cline { 2 - 5 } & $3.08 \%$ & $40 \%$ & $44.62 \%$ & $12.31 \%$ \\
\hline
\end{tabular}

Table 6. The methods of instruction

\begin{tabular}{|l|l|l|l|l|}
\hline Numberlchoice & A & B & C & D \\
\hline \multirow{2}{*}{6} & very helpful & helpful & adequate & not helpful \\
\cline { 2 - 5 } & $13.85 \%$ & $46.15 \%$ & $27.69 \%$ & $12.31 \%$ \\
\hline
\end{tabular}

Table 7. The revision of students' compositions

\begin{tabular}{|l|l|l|l|l|}
\hline Numberlchoice & A & B & C & D \\
\hline \multirow{2}{*}{7} & very helpful & helpful & adequate & not helpful \\
\cline { 2 - 5 } & $7.69 \%$ & $56.92 \%$ & $24.62 \%$ & $10.77 \%$ \\
\hline
\end{tabular}

Table 8. Students' Progress

\begin{tabular}{|l|l|l|l|l|}
\hline Numberlchoice & A & B & C & D \\
\hline $\mathbf{8}$ & very good & good & adequate & poor \\
\cline { 2 - 5 } & $1.54 \%$ & $40 \%$ & $40 \%$ & $18.46 \%$ \\
\hline
\end{tabular}

Table 9. Students' achievement of their goals

\begin{tabular}{|l|l|l|l|l|}
\hline Numberlchoice & A & B & C & D \\
\hline $\mathbf{9}$ & fully & almost fully & adequately & poorly \\
\cline { 2 - 5 } & $4.62 \%$ & $10.77 \%$ & $66.15 \%$ & $18.46 \%$ \\
\hline
\end{tabular}

Table 10. The influences of the given material on writing tasks

\begin{tabular}{|l|l|l|l|l|}
\hline Numberlchoice & A & B & C & D \\
\hline $\mathbf{1 0}$ & big & little & average & none \\
\hline & $27.69 \%$ & $10.77 \%$ & $61.54 \%$ & $0 \%$ \\
\hline
\end{tabular}

Table 11. The gap between the sample summary and students' summaries

\begin{tabular}{|c|c|c|c|c|}
\hline Number/choice & $\mathrm{A}$ & B & $\mathbf{C}$ & D \\
\hline \multirow[t]{2}{*}{11} & big & small & average & none \\
\hline & $36.92 \%$ & $16.92 \%$ & $44.62 \%$ & $1.54 \%$ \\
\hline
\end{tabular}


Table 12. The writing tasks helpful to improve students' writing level

\begin{tabular}{|l|l|l|l|l|l|l|}
\hline Numberlchoice & A & B & C & D & E & F \\
\hline 12 & $\begin{array}{l}\text { just list a } \\
\text { topic }\end{array}$ & $\begin{array}{l}\text {. first read an original } \\
\text { essay and then list some } \\
\text { topics }\end{array}$ & $\begin{array}{l}\text { analyze an } \\
\text { essay }\end{array}$ & $\begin{array}{l}\text { write a summary } \\
\text { or book report }\end{array}$ & $\begin{array}{l}\text { Any practical } \\
\text { writing }\end{array}$ & $\begin{array}{l}\text { Other } \\
\text { forms }\end{array}$ \\
\cline { 2 - 6 } & $18.46 \%$ & $46.15 \%$ & $30.77 \%$ & $32.30 \%$ & $46.15 \%$ & $6.15 \%$ \\
\hline
\end{tabular}

Table 13. The factors to be focused on in reading

\begin{tabular}{|l|l|l|l|l|l|}
\hline Number/choice & A & B & C & D & E \\
\hline \multirow{2}{*}{13} & $\begin{array}{l}\text { Cultural } \\
\text { factors }\end{array}$ & vocabularies & stylistic features & deep thoughts & Other information \\
\cline { 2 - 6 } & $47.69 \%$ & $33.85 \%$ & $60 \%$ & $43.08 \%$ & $13.85 \%$ \\
\hline
\end{tabular}

Table 14. The factors to be considered in writing

\begin{tabular}{|l|l|l|l|l|l|}
\hline Number/choice & A & B & C & D & E \\
\hline \multirow{2}{*}{14} & $\begin{array}{l}\text { cultural } \\
\text { factors }\end{array}$ & vocabularies & stylistic features & deep thoughts & $\begin{array}{l}\text { other } \\
\text { information }\end{array}$ \\
\cline { 2 - 6 } & $32.31 \%$ & $27.69 \%$ & $52.31 \%$ & $64.62 \%$ & $10.77 \%$ \\
\hline
\end{tabular}

\section{Questionnaire}

Class

Name

1. Your overall impression of the writing course is
A. very positive
B. positive
C. less than positive
D. negative

2. The amount of reading material is
A. too great
B. sufficient
C. adequate
D. insufficient

3. The amount of written work is
A. too great
B. sufficient
C. adequate
D. insufficient

4. The level of difficulty is
A. too high
B. good
C. fair
D. poor

5. The balance between theory and practice is
A. very good
B. good
C. fair
D. poor

6. The method of instruction is
A. very helpful
B. helpful
C. adequate
D. not helpful

7. The revision of student compositions and problems is
A. very helpful
B. helpful
C. adequate
D. not helpful

8. Your progress has been
A. very good
B. good C. adequate
D. poor

9. Your goals and expectations have been met
A. fully
B. almost fully
C. adequately
D. poorly

10. Teachers may assign you writing assignments after you finish reading some related passages. When you write, the influence of the original passages is
A. big
B. little
C. average
D. none

11. When you summarize an article, you find the gap between your summary and the sample summary is
A. big
B. small
C. average
D. none

12. Do you think what kind of assignments will be more helpful to your level of writing?
A. just list a topic
B. first read an original essay and then list some topics 
$\begin{array}{lll}\text { C. analyze an essay } & \text { D. write a summary or book report E any practical writing F. other forms }\end{array}$

13. When you read essays written by foreign students or professionals, what information are you usually more concerned with?
A. cultural factors
B. vocabularies
C. stylistic features
D. deep thoughts

E. other information

14. When you write an essay, what information do you usually take into consideration?
A. cultural factors
B. vocabularies
C. stylistic features
D. deep thoughts
E. other information 